\title{
Family conflict and non-family managers in family business: A Pitch
}

\author{
Nikola Roseckáa ${ }^{\mathrm{a}, 1}$ and Ondřej Machek ${ }^{\mathrm{a}}$ \\ ${ }^{a}$ University of Economics in Prague, Czech Republic
}

\begin{abstract}
From the research viewpoint, conflicts in family firms belong to very challenging research areas. At the same time, the literature is fragmented, and it is not easy to identify and articulate a clear research question in this research domain. Based on Faff's $(2015,2019)$ pitching research template, we develop a real pitch and describe our experience with its use from the student's and supervisor's viewpoints. The research question is: "What is the role of non-family managers in family conflicts in family firms?" This pitching research letter also presents personal reflections on the pitching template application.
\end{abstract}

Keywords: Non-family managers, family business, pitching research, pitching template.

JEL codes: M10, L22

\section{Introduction}

The application for Ph.D. studies requires a well-elaborated research plan which includes a literature review, the expected data, the methodology, and the contributions. As the doctoral student gradually learns more and more about the topic of interest, the focus of the dissertation may develop over time, and it frequently becomes narrow and more specific than the original research project. Faff's $(2015,2019)$ pitching research template is a useful tool which allows for addressing the need for presenting the research plan in a simple and understandable manner as well as for clarifying one's own thoughts. This pitching research letter

${ }^{1}$ Corresponding author: Faculty of Business Administration, University of Economics, Prague; nam. W. Churchilla 4, 13067 Prague, Czech Republic; tel. (+420) 224098653 , email address: nikola.rosecka@vse.cz 
(PRL) is prepared by a Ph.D. student and her supervisor and elaborates on the perceived advantages from both viewpoints. The supervisor of the Ph.D. thesis was first made familiar with the pitching research template in 2016 during prof. Faff's visit to his home institution. After prof. Faff's workshop, the template was subsequently adopted and used by multiple employees of our institution. Consequently, it is also sometimes recommended to Ph.D. students for presenting the research progress during regular colloquia. This PRL deals with a "real pitch" focusing on the field of family business research. Partly also thanks to the pitching research template, we managed to find a relatively narrow topic of interest. Having started with a vast topic ("conflicts in family firms"), we narrowed the research idea down. We found an unexplored, yet a very relevant topic of the role of nonfamily managers in family conflict and family firms.

The rest of this PRL is organized in the following manner. First, we present a brief commentary on the pitch and present the pitching template. Subsequently, we elaborate on our personal reflections on the pitching template application. Finally, we provide a conclusion.

\section{Commentary on the Pitch}

We aim to investigate the role which non-family managers play in family conflicts in family firms. Table 1 displays the completed pitching template. Following Faff's $(2015,2019)$ guidelines, the key papers do not include seminar papers, but are recent and relate to the main research question. We include the recent paper of Hiebl and Li (2018) as this is one of the studies which point out that non-family managers act as mediators in conflicts between family members. Family conflicts and tensions are not eliminated but partly transferred to conflicts between family and non-family managers. Second, the paper of Hiebl (2013) provides us with a qualitative study related to non-family chief-financial officers (CFOs). This paper analyses the role of multiple family tribes in a family business which may give conflicting instructions to non-family CFOs. They may, in turn, voluntarily leave the firm. In other words, family conflict can lead to non-family managers' turnover. Third, we include a review of literature presented by Tabor et al. (2017). The paper mainly focused on the role, effects and challenges related to non-family members in the family business. At the same time, the authors emphasize that nonfamily managers represent an underresearched area in family business literature and more studies about the recruitment process and outcomes resulting from their employment are needed. 
Table 1. The pitch template on the role of non-family managers in family conflicts in family firms

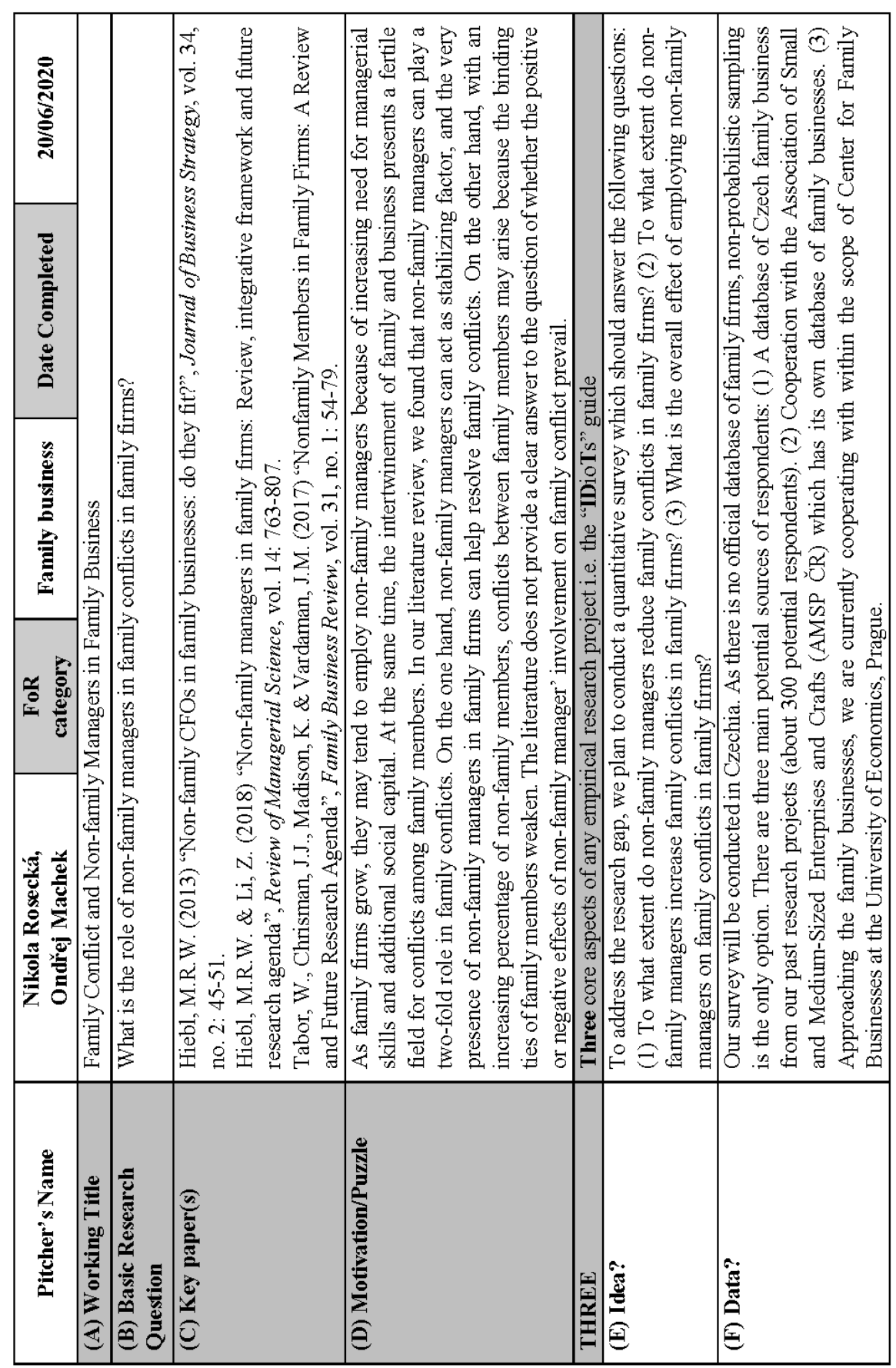




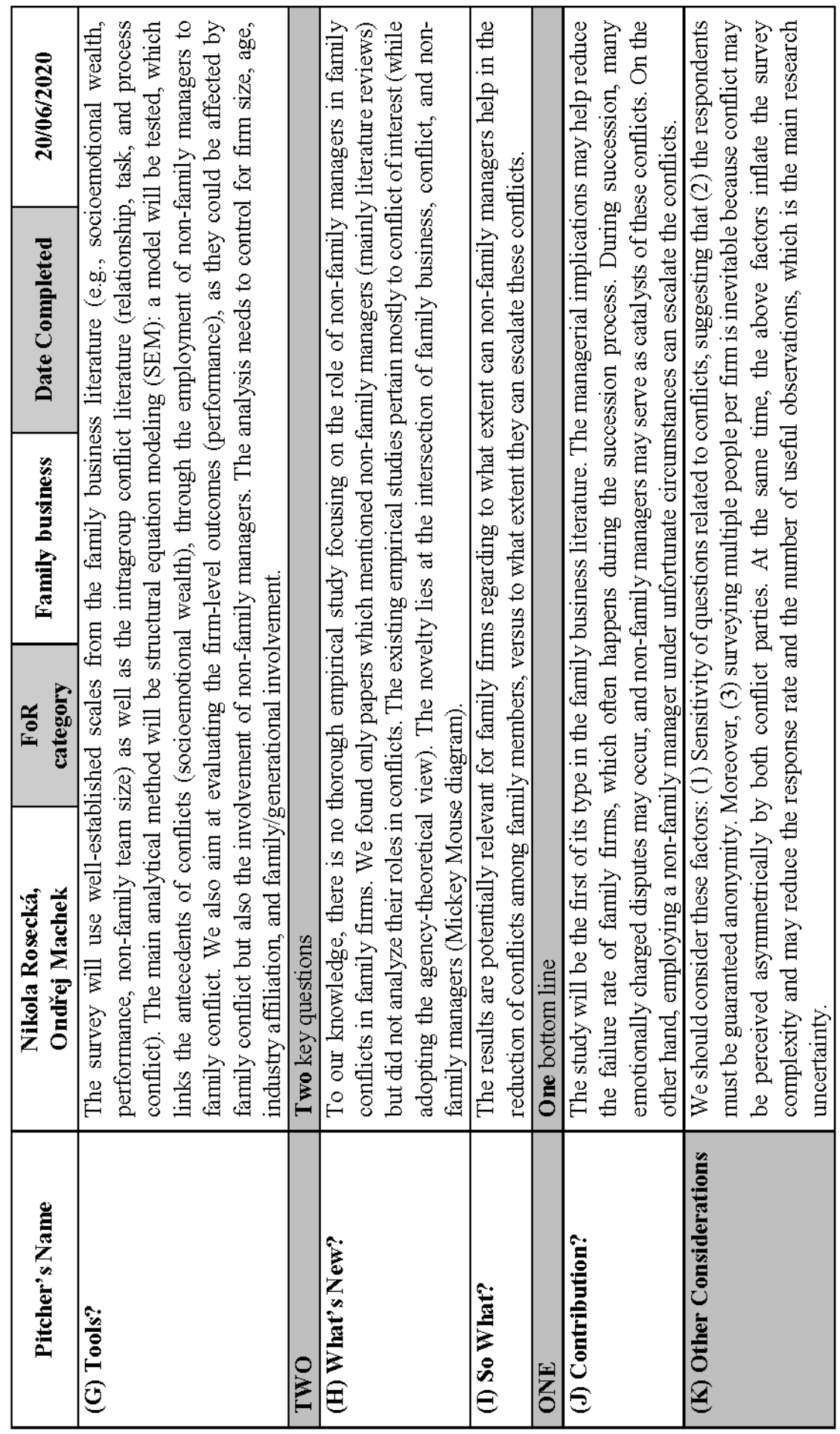


Because of the nature of our research question, the research will be quantitative, and we will try to survey multiple people per firm. There are two main areas to analyze. First, we need to analyze if the presence of non-family managers reduces or increases family conflict. Second, we need to identify the overall effect which non-family managers have on family business while considering other variables, such as firm size, family ownership, the generation in charge, etc. The core theoretical approaches will be the intragroup conflict theory and the theoretical foundations of family business, especially the socioemotional wealth approach. The above-mentioned theories allow us to outline the Mickey Mouse diagram characterizing the novelty of our research idea (Fig. 1). The diagram is composed of three circles: "family business" as the core type of business that we investigate, and two circles representing two key research areas which still lack empirical evidence in the family business literature: "non-family managers" (meaning the role which they play in the family business and what effects they have on the business as a whole, see, e.g. Tabor et al. (2017)), "conflict" (a traditional topic of the family business literature, which is however insufficiently explored in terms of empirical evidence, see, e.g. Kubíček and Machek, 2020). Our research question is located at the intersection of these three circles.

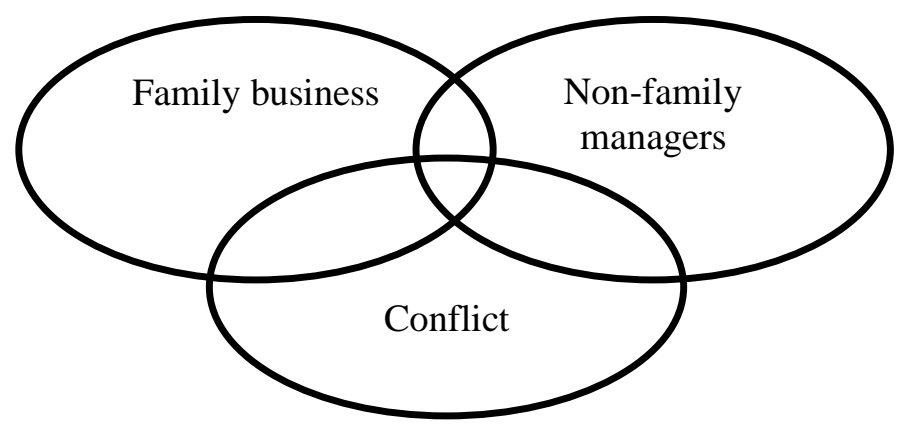

Figure 1. Mickey Mouse diagram characterizing novelty of research idea

\section{Personal reflections on the pitching template application}

The pitch was completed by two authors within a few days. However, prior to completing it, we performed a literature review related to the role of non-family managers in family firms. At our home institution, the pitching template has been used by several students and supervisors (e.g., Dvouletý, 2017; Jurek, 2018). It is clear that the template has added value for both parties. For students, the pitching template helps identify important categories of the dissertation thesis but also helps outline a preliminary idea about survey questions. More specifically, the pitch helped the doctoral student clarify the research question and identify the subsections which should be included in the research. Moreover, the identification of variables, potential sources of data and tools which will measure these variables are essential for the research success and should be done in advance. Even before a 
thorough review of literature is made, the awareness of "what is new" and "why is that useful" is critical. With the help of the pitching template, we are more confident that the most relevant variables are included in the survey. Second, the pitching template is very suitable for presenting the research progress during a doctoral colloquium. The template is clear, brief and summarizes all important categories which should be taken into consideration. Thus, the pitch can also be seen as a useful tool for presenting the research to other colleagues. Those, in turn, may point out new ideas and suggestions which can be very relevant for the improvement of the research. The supervisor agrees that the pitch helped both parties clarify the scope of the dissertation.

\section{Conclusion}

In this pitching research letter, we develop and present the personal experience with the pitching template of professor Faff $(2015 ; 2019)$. Overall, our experience with the template is very positive, and we may suggest it to Ph.D. candidates but also their supervisors. We believe that the template is useful not only to people who learn how to conduct research but also to more experienced researchers.

\section{References}

Dvouletý, D. (2017) "Determinants of Nordic entrepreneurship: A reverse engineered pitch", Accounting and Management Information Systems, vol. 16, no. 3: 420-426

Faff, R.W. (2015) “A simple template for pitching research", Accounting and Finance, vol. 55: 311-336

Faff, R.W. (2019) "Pitching research", available at SSRN: http://dx.doi.org/10.2139/ssrn.2462059

Hiebl, M.R.W. (2013) "Non-family CFOs in family businesses: do they fit?", Journal of Business Strategy, vol. 34, no. 2: 45-51

Hiebl, M.R.W. \& Li, Z. (2018) "Non-family managers in family firms: Review, integrative framework and future research agenda", Review of Managerial Science, vol. 14: 763-807

Jurek, M. (2018) "Hybrid venture capital fund raising in emerging markets: A pitch", Accounting and Management Information Systems, vol. 17, no. 1: $167-177$

Kubíček, A. \& Machek, O. (2020) "Intrafamily conflicts in family businesses: a systematic review of the literature and agenda for future research", Family Business Review, vol. 33, no. 2: 194-227

Tabor, W., Chrisman, J.J., Madison, K. \& Vardaman, J.M. (2017) "Nonfamily members in family firms: a review and future research agenda", Family Business Review, vol. 31, no. 1: 54-79 